\title{
A COMPREENSÃO HEIDEGGERIANA DE ESPAÇO COMO ELEMENTO CONSTITUTIVO DA ESTRUTURA SER-NO-MUNDO
}

\author{
La compréhension heideggerienne de l'espace comme élément contitutive de la \\ structure être-au-monde
}

\author{
Rafael da Silva Paes Henriques \\ UFES
}

\begin{abstract}
Resumo: Este artigo tem o objetivo de desconstruir o modo como cotidianamente compreendemos a natureza do espaço como extensão. Para tanto, pretendemos apresentar como contraponto a esse entendimento, a compreensão heideggeriana de espaç. Em Heidegger, ao invés de algo fora separado e apartado do sujeito, o espaço é uma dimensão constitutiva daquilo que é a experiência que nós somos. Para cumprir com esses objetivos, vamos seguir de perto, principalmente, a obra Ser e tempo.
\end{abstract}

Palavras-chave: Heidegger; Espaço; Ser-no-mundo; Descartes; Res extensa.

Summary: The paper aims to deconstruct the way how we daily understand the nature of space as extension. To do this, we aim to present a different perspective of that understanding: the Heideggerian understanding of space. In Heidegger, instead of something external to the subject, space is a constitutive dimension of what is the experience we are. We all take the book Being and Time as the primary source.

Keywords: Heiddeger; space; being-in-the-world; Descartes; Res extensa

Resumé: Cet article a le but de déconstruire la manière dans laquel quotidiennement on comprendre la nature de l'espace, comme extension. En ce sens, on a l'objectif de présenter, en contrepartie, la compréhension heideggerienne de l'espace. Chez Heidegger, au lieu de quelque chose de l'exterieur, séparée et dissociée de ce qui est le sujet, l'espace est une dimension constitutive de ce qui est l'expérience que nous mêmes sommes. Pour attendre ces objectifs, nous allons suivre à proximité, principalement, l'oeuvre Être et Temps.

Mots-clés: Heidegger; Espace; Être-au-monde; Descartes; Res extensa.

\section{Introdução}

Este artigo pretende dar alguns passos atrás, com o intuito de problematizar a compreensão de espaço que, na maioria das vezes, orienta não somente nossa lida cotidiana, como também nossa forma de entender aquilo que somos, aquilo que é o mundo, e, consequentemente, a maneira como nos relacionamos com ele. Nossa argumentação tem a intenção de apontar que esse modo distraído e rotineiro de apropriação do que é o espaço também é assumido antecipadamente por boa parte das investigações científicas e filosóficas de nosso tempo. Torna-se urgente, dessa maneira, realizar uma espécie de retorno ao começo; regresso ao princípio daquilo que hoje se apresenta como posto e encerrado. Rever a natureza do espaço é rever uma apropriação que se mostra tão acabada, que serve de ponto de partida para os mais variados estudos, nas mais diversas áreas do conhecimento.

Para tanto, o esforço deste texto será o de pôr em suspensão o modo como habitualmente se compreende o que é o espaço, para que, assim, se possa explicitar os 
propósitos desse modo de entendimento, que se apresenta como óbvio. Esclarecendo o encaminhamento dessa apropriação, torna-se possível, então, buscar novamente algum solo ontológico para a questão. A ideia é que, desde esse novo fundamento para o que venha a ser espaço, uma forma menos automática e evidente de se compreender mundo, homem e, principalmente, mas ao mesmo tempo, sua relação com a dimensão espacial da existência, se torne possível. Pretende-se superar o entendimento de que se vive simplesmente dentro do espaço numa relação de conteúdo e continente, tal como a roupa está dentro do armário ou como as pessoas podem estar dentro do carro. O que se quer apontar é que nossa ligação com o espaço não é algo da ordem do que é contingente, ou seja, que pode ou não se realizar, ou como se a dimensão espacial da existência humana fosse de uma natureza tal que primeiramente (no sentido ontológico) houvesse os termos da relação: nós e os mais variados objetos, situados nos mais diversos espaços disponíveis, e apenas depois se realizasse uma conexão possível entre esses dois pólos opostos que fundamentariam a experiência.

Na perspectiva heideggeriana, ao contrário, é sempre desde um dado horizonte, no qual sempre já se está "inserido", que tudo o que é vem a ser, o que inclui a nós mesmos e também o modo como entendemos que a realidade se organiza, isto é, aquilo que são propriamente as "coisas" com as quais nos relacionamos. Isso, é claro, implica também aquilo que vem a ser o espaço, ou mellhor, no modo como compreendemos o que é espaço. Essa maneira de entender fundamento de existência não compreende princípio ontológico como sendo o resultado do arbítrio de alguém, como uma má-compreensão subjetivista poderia supor, e também não o define como sendo igulal a natureza objetiva, sinônimo de conjunto de essências imutáveis, com caráter de substância, que teria por qualidade oferecer a sua "mesmidade" para ser revelada pelo homem. Nem subjetivismo, nem objetivismo, muito menos síntese de dois termos como se ambos pudessem ser anteriores a experiência. O que se pretenderá indicar aqui é que é desde uma perspectiva, que sempre já se deu, que a existência se fundamenta.

Nesse sentido, o que é ontologicamente primeiro é uma possibilidade que realiza tanto o que compõe o homem quanto organiza o mundo, de maneira que essas duas dimensões da existência - sujeito e objeto - não são substratos autônomos e independentes da realidade, mas constituem-se como dimensões do real que se produzem a cada e em toda experiência. Não se quer, desse modo, afirmar a inexistência ou mesmo a indistinção entre sujeito e objeto. O que se pretende esclarecer é que a separação estabelecida pela tradição metafísica, sujeito-objeto, que é quase "naturalmente" entendida como sendo o fundamento da realidade, não é fundamento de nada, já que, na experiência, fenomenologicamente, essa cisão é tardia, epigonal, ou seja, é o resultado de um modo de realização de real e não princípio ontológico. Logo, a maneira como se deve compreender, inclusive o que é o espaço, é o resultado de uma possibilidade que sempre já se realizou, que sempre já se completou, não havendo fora ou antes de experiência. O espaço é, assim, constitutivo, isto é, é um elemento que compõe essa dinâmica, sendo o homem espacial em seu sentido originário, como se tentará explicitar neste trabalho. "O espaço nem está no sujeito nem o mundo está no espaço. Ao contrário, o espaço está no mundo na medida em que o ser-no-mundo constitutivo da pre-sença já descobriu sempre um espaço" (HEIDEGGER, 2005, p. 161). Ser-no-mundo e pre-sença, como veremos, são termos cunhados por Heidegger, que evocam um momento e o próprio processo de constituição ontológica de homem e mundo, isto é, apontam para uma dimensão e para o modo de realização de experiência, existência.

Dito de outro modo, este artigo tem por objetivo, realizar uma dupla tarefa. Em primeiro lugar, se quer repensar origem, isto é, o envio desde o qual muitas noções fundamentais se tornaram praticamente automáticas, como se já estivessem definitivamente decididas e superadas de modo a não valer mais a pena ou não fazer mais sentido questionar seu direito à existência. É esse o caso quando se define a natureza, ou seja, a essência do espaço como sendo extensão. Essa antiga compreensão configura-se como um tipo de a priori incontornável e inquestionável, até os dias atuais. 
Nesse contexto, espaço é uma espécie de pré-objeto; algo dotado de comprimento, altura e largura no qual e desde o qual todos os objetos se encontram dispostos. Primeiro é preciso haver espaço, como condição de possibilidade, para que, em seguida, todos os objetos possam encontrar-se disponíveis.

Em vez de também tomar esse entendimento como pressuposto, se quer aqui, desde Heidegger, realizar uma espécie de recuo ontológico em busca de fundamento, se quer rever o que se assume despreocupadamente como a priori inevitável, com o objetivo de descrever e desconstruir os modos como distraidamente compreende-se esse que é um dos entendimentos mais elementares da nossa experiência: o espaço como extensão. A busca de origem pretende revelar que, o que se apresenta como obviamente já resolvido, possui uma história, uma origem (gênese) e um encaminhamento (destino). 0 trabalho assume, assim, um deslocamento evidente: quer repensar o começo, suspender os pressupostos. Como isso? Por que isso? Desde quando isso? A partir de que perspectiva? Afinal o que é primeiro? Onde é o princípio?

A segunda tarefa que pretendemos cumprir é derivada, mas de alguma forma deve ser cumprida ao mesmo tempo da primeira. Além de desconstruir o modo como cotidianamente compreendemos a natureza do espaço, temos o objetivo de apresentar a compreensão heideggeriana de espaço, conforme já esboçamos e pretendemos explicitar melhor no decorrer deste trabalho. Nesse encaminhamento, ao invés de algo fora, separado e apartado do sujeito, o espaço é uma dimensão constitutiva daquilo que é a experiência que nós somos. Para cumprir com esses objetivos, vamos seguir de perto, principalmente, a obra Ser e tempo, de 1927. Para Heidegger, a essência do homem, ou seja, sua natureza, é algo marcado não por uma interioridade anterior à experiência, visto que se realiza e se efetiva na experiência. Por isso, o autor denomina a natureza do homem de Dasein, ser-aí, noção que, no Brasill, também é traduzida como pre-sençat. Com essa definição, Heidegger quer apontar que o que entendemos como sujeito é uma estrutura e uma experiência de imersão, sendo que um de seus momentos constitutivos é ser-no-mundo, daí que afirmamos anteriormente que o espaço é uma dimensão constitutiva da experiência que nós somos.

O espaço não se encontra no sujeito nem o sujeito considera o mundo 'como se' estivesse num espaço. É o 'sujeito', entendido ontologicamente, a pre-sença, que é espacial em sentido originário. Porque a pre-sença é nesse sentido espacial, o espaço se apresenta como a priori. Este termo não indica a pertinência prévia a um sujeito que de saída seria destituído de mundo e projetaria de si um espaço. Aprioridade significa aqui precedência do encontro com o espaço (como região) em cada encontro do manual no mundo circundante (HEIDEGGER, 2005, p. 161).

Isso quer dizer que, no processo de constituição ontológica daquilo que nós somos, há, e sempre haverá, uma dimensão espacial. Não tem de um lado o vazio e em seguida o homem que se insere no espaço ou que determina, ao seu modo, o que vem a ser o espaço projetando seu arbítrio. O que a citação aponta como sendo um a priori não deve ser entendido como um acontecimento que se completa e se realiza antes da experiência. Se quer, na verdade, indicar que nossa experiência é sempre espacial. Em cada possibilidade de existência, numa lida, numa tarefa - por isso, do que está à mão para uma finalidade (manual) - em um determinado entorno, num certo contexto, numa possibilidade (mundo circundante). Para Heidegger, a essência do existir reside em sempre, e a cada vez, estar imerso na rede significativa que é o mundo (ser-no-mundo).

Na medida em que nossos objetivos e hipótese de trabalho já estão expostos, resta agora explicitar melhor como o pensamento heideggeriano opera a desconstrução

\footnotetext{
${ }^{1}$ Em nota explicativa (N1) publicada na edição brasileira de Ser e Tempo, editada pela Vozes, Márcia Sá Cavalcante Schuback explica que "pre-sença não é sinônimo de existência e nem de homem [...] Evoca o processo de constituição ontológica de homem, ser humano e humanidade. É na pre-sença que o homem constrói o seu modo de ser, a sua existência, a sua história e etc" (HEIDEGGER, 2005, p. 309). Na mesma nota, Márcia Schuback esclarece por quê optou por pre-sença, em vez de traduzir Dasein por ser-aí, "[....] para superar o imobilismo de uma localização estática que o ser-aí poderia sugerir. O 'pre' remete ao movimento de aproximação, constitutivo da dinâmica do ser, através das localizações" (Idem).
} 
da forma moderna de compreensão de homem e mundo, o que inclui de modo especial a noção de espaço, para propor uma nova maneira de estabelecer um solo ontológico para aquilo que nós somos, o que inclui nossa relação com a dimensão espacial da existência.

\section{Descartes e a compreensão moderna de espaço}

É justamente por acreditar que subjetividade e objetividade realmente não são bons parâmetros para se acessar de maneira originária o mundo e para determinar a verdade última de todas as coisas, que Heidegger desconstrói de maneira exemplar a compreensão de mundo assumida por Descartes. A perspectiva cartesiana é um exemplo paroxístico de uma interpretação da realidade, cunhada na modernidade, que opera a partir da disjunção de sujeito e objeto e que compreende o espaço como propriedade basilar da realidade: Descartes assenta na extensão seu solo ontológico fundamental. É a partir dessa substância, que tudo o que é viria a ser. "A extensão é a constituição ontológica do ente em causa que deve "ser" antes de quaisquer outras determinações ontológicas a fim de que estas possam "ser" o que são. A extensão deve, portanto, "ser atribuída" em primeiro lugar a coisa corpórea" (HEIDEGGER, 2005, p. 136).

Com efeito, nessa perspectiva, por maior que sejam as diferenças acidentais que podemos encontrar na natureza, há algo que subsistiria sempre o mesmo. O que se mostra, em um primeiro momento, como sendo características fundamentais da realidade seriam apenas qualidades acessórias que giram em torno de algo que permanece constante. A ideia desse procedimento é abandonar, de uma vez por todas, tudo o que seja externo a própria coisa, ou seja, do âmbito das aparências, para se concentrar na maneira como elas são "verdadeiramente" constituídas. Uma pedra, por exemplo, pode ser cinza, de superfície rugosa, de formato irregular, pesada e ser composta de certos tipos de minerais. Mas essas características são apenas periféricas. 0 que se quer realmente saber é o que faz com que todas as pedras, mesmo com todas as diferenças que podem ser identificadas na realidade, continuem sendo pedras. A "coisa mesma" seria, qualquer que fosse a coisa, um núcleo em torno do qual se pode verificar uma série de propriedades; uma espécie de suporte perene para certas características e não outras. "Na coisa dotada de extensão como tal fundam-se, de iníício, as determinações que se mostram como qualidades, mas que, "no fundo', são modificações quantitativas dos modos da própria extensio" (HEIDEGGER, 2005, p. 145).

Dessa forma, em Descartes, antes de mais nada, a coisa é um substrato capaz de carregar e manifestar uma série de atributos que não fazem parte de sua essência, mas que podem ser "acrescentadas" à sua objetividade primeira. Essa espécie de continente de qualidades nunca muda, é constante e, justamente por isso, constitui-se como o único conhecimento sobre a coisa no qual podemos confiar. Como somatório de uma série de coisas corpóreas, a res extensa é o conjunto de objetos que, num primeiro momento, nos revelam apenas seus atributos secundários e acidentais cuja variação se deve a algo mais profundo e que é anterior a nossa experiência com a realidade: a substância. Como consequência maior dessa interpretação, a extensão é a "coisalidade" de toda e qualquer coisa existente, ou seja, é a possibilidade que permite que tudo aquilo que é se realize. Desse modo, a extensão não é apenas o espaço, que pode ser medido e determinado em sua altura, largura e comprimento, mas ela é o próprio real. A extensio é o caráter ontológico desde o qual o ente, em seu todo, vem ao nosso encontro e deixa o ente em geral aparecer desde um certo princípio.

As substâncias são acessíveis em seus "atributos" e cada substância possui uma propriedade principal a partir da qual a essência da substancialidade de uma determinada substância pode ser recolhida. [...] A saber, a extensão em comprimento, altura e largura constitui o ser propriamente dito da substância corpórea que nós chamamos "mundo" (HEIDEGGER, 2005, p. 135-136).

Nesse horizonte, as propriedades e características das coisas devem ser investigadas, não porque são a essência daquilo com o que lidamos cotidianamente, mas porque tornam-se vias de acesso a uma propriedade principal, ou seja, é preciso, então, 
buscar a característica primeira, que torna possível a existência de todos os outros atributos. Isso porque cada substância, que subsiste e é constante, possuiria uma propriedade principal. $\mathbb{E}$ para a sua "descoberta" que todo esforço de investigação deve estar voltado. Todo o horizonte de interpretação cartesiano está baseado, desse modo, na extensão como "ser propriamente dito" daquilo que chamamos mundo.

Desde extensão como fundamento de tudo, não é preciso muito esforço para se fazer uma lista das propriedades sensíveis de qualquer objeto palpável. O mais desconcertante na desconstrução operada por Heidegger é a revelação de que boa parte da história da filosofia não disse nada mais além disso sobre as coisas: descrições de atributos. Trata-se de uma severa crítica aos caminhos e ao percurso no qual a pergunta pela realidade última do real se desenhou e foi desenhada pelo Ocidente. O grande problema apontado pelo autor é a esterilidade produzida por uma resposta pronta e acabada que teve por intenção dar conta de maneira cabal e definitiva da pergunta pela coisa. "Então, o que é uma coisa? Resposta: urma coisa é o suporte subsistente de muitas propriedades que nela subsistem e se transformam" [tradução nossa] (HEIDEGGER, 2011$, p. 45) $)^{2}$.

É exatamente por apresentar uma resposta pretensamente derradeira para a pergunta pelo modo de estruturação e organização da realidade que, para Heidegger, esse horizonte de compreensão é insuficiente para dar conta da dinâmica de manifestação das coisas. Ele chama essa interpretação de "concepção natural do mundo", uma vez que faz abstração de toda a metafísica profunda e de toda a teoria elevada. E mais que isso: essa perspectiva não questiona sua própria fundamentação ontológica, tomando como pronto o que deveria ser discutido e analisado com bastante cuidado e atenção. O professor Gilvan Fogel destaca o risco contido no esquematismo desse horizonte de análise: o problema é encarar como "evidente", "óbvio" e "natural" essa determinação da realidade.

[...] igualmente perigoso é o risco de cair no roldão, no turbilhão da indiferença e da apatia, que define aquela certeza sedimentada, a qual, sob esta crosta ou cascão da sedimentação, vela uma reação afoita e desesperada no intuito de tapar, de exorcizar o perigo rebentado, instaurando assim o "natural" que é a voragem da "evidência", da normalidade - o liso das coisas, o sem sobressaltos no viver (FOGEL, 1998a, p. 113).

O decisivo, no caminho de Descartes, é que ele igualou o ser à constância do ser simplesmente dado, sem explicar minimamente o direito com que se pode fazer essa gigantesca operação. E foi justamente a partir dessa ideia de ser que a concepção cartesiana prescreveu ao mundo o seu próprio ser. O erro está na base, no princípio ontológico desde o qual se estabelece a definição de todo e qualquer ente que se realiza. Se os entes se efetivam a partir de extensão, temos como consequência "natural" que é com o domínio e o controle da dimensão ôntica da realidade que a investigação filosófica deve se ocupar.

Descartes radicalizou o estreitamento da questão do mundo, reduzindo-a à questão sobre a coisalidade da natureza enquanto ente intramundano acessível em primeiro lugar. Consolidou a opinião de que o conhecimento ôntico de um ente, pretensamente o mais rigoroso, também constitui a via de acesso possível para o ser primário do ente que se desencobre neste conhecimento. Trata-se, no entanto de perceber também que mesmo as "complementações" da ontologia da coisa movem-se, em princípio, sobre a mesma base dogmática de Descartes (HEIDEGGER, 2005, p. 147).

O problema é que essa descrição fica presa aos entes, é ôntica e não investiga fenomenologicamente o mundo. Não que essa seja uma maneira errada de perguntar pela realidade do real. Ao contrário, ela quase sempre está correta na exposição das

\footnotetext{
${ }^{2}$ Qu'est-ce donc qu'une chose? Réponse: une chose est le support subistant de beaucoup de propriétés
} subsistant en elle et s'y transformant. 
características e propriedades da natureza. E o mundo pode mesmo ser "descoberto" seguindo-se caminhos e graus diferentes. A questão radical proposta por Heidegger é que, seguindo esse caminho ôntico, ou mesmo o caminho no qual se busca o ser das coisas naturais entendendo-o como substancialidade, nem ao menos se consegue perguntar ontologicamente pelo fenômeno do mundo. "Nem um retrato ôntico dos entes intramundanos nem a interpretação ontológica do ser destes entes alcançariam, como tais, o fenômeno do 'mundo'. Em ambas as vias de acesso para o ser "objetivo' já se "pressupõe', e de muitas maneiras, o 'mundo" (HEIDEGGER, 2005, p. 104).

É por isso que Heidegger propõe uma leitura do real bastante distinta da cartesiana. Nela o homem, enquanto ente, se realiza na estrutura ser-no-mundo. Com a expressão não se quer afirmar que exista uma indistinção ou continuidade entre a presença (Dasein) e os demais entes, muito menos que primeiro exista o "mundo" e que depois o homem se encaixa ao "mundo natural". O homem não está no mundo da mesma forma como podemos estar dentro de uma sala, onde primeiro é preciso que exista a sala, com todas as suas propriedades e características já dadas, e depois existe o homem que também chegaria pronto e se inseriria dentro da sala.

A expressão ser-no-mundo significa, antes de mais nada, um estar familiarizado a. Desse modo, a relação do homem com o mundo é uma espécie de estar sempre e imediatamente já tomado por, sempre já inserido. "É um engajamento pré-reflexivo, que se cumpre independentemente do sujeito por um liame mais primitivo e fundamental do que o nexo entre sujeito e objeto admitido pela teoria do conhecimento" (NUNES, 2004, p. 14). O mundo no qual estamos o tempo inteiro, e do qual não podemos "escapar", não é um substrato, um receptáculo de objetos. Isso porque é somente em um mundo que os entes se tornam acessíveis para nós, inclusive a própria pre-sença, o próprio homem, não pré-existe a nenhum mundo dado e circunscrito.

[...] o índice elementar, o proto-esquema ou o "átomo" de todo real possível é uma estrutura, o complexo de uma unidade simples (é isso a "totalidade"), que se denomina "ser-no-mundo". O real, todo real possível, o é à medida que se dá ou é para um ente que é ou está na determinação de ser na compreensão do real. [...] "Ser-no-mundo", esta estrutura, é pois a "hora", o "instante" do real - de todo real possível (FOGEL, 1998b, p. 133-134).

Dessa maneira, para que o espaço, na forma de extensão, seja a realidade primeira de todo e qualquer ente, é preciso que, antes, uma concepção de mundo já esteja operando. A extensio, como solo ontológico, padece de explicação e não dá sustentação suficiente para toda a ontologia ao modo moderno, uma vez que desde essa base, não se pergunta originariamente pelo mundo; não há lugar para se investigar a existência de algo que seja anterior. Será mesmo que não nos é possível pensar a realidade fenomenologicamente antes de espaço como extensão? Ou, ao contrário, a natureza como res extensa é que, na realidade, já pressupõe e impõe uma perspectiva ao mundo que se realiza?

Para Heidegger, o horizonte cartesiano, e também todas as outras leituras posteriores, buscaram um a priori, se serviram de uma instância anterior a toda e qualquer experiência para, a partir dela, realizarem ontologias descritivas que se limitavam a executar retratos ônticos do real, por não discutir e analisar a fundo a sua compreensão do ser, ou seja, por não investigar o direito a existência dessa espécie de a priori como possibilidade para que mundo se faça mundo. A realidade se estruturando como a oposição de res cogitans e res extensa já é claramente uma interpretação possível de mundo que precisa ser problematizada.

Quando, porém, lembramos que a espacialidade manifestamente também constitui o ente intramundano, torna-se, enfim, possível uma "recuperação" da análise cartesiana do "mundo". Com a explicação radical da extensio como praesuppositum de toda a determinação da res corporea, Descartes preparou a compreensão de um a priori, cujo conteúdo foi fixado posteriormente por Kant, de maneira mais penetrante. Dentro 
de certos limites, a análise da extensio independe da falta de uma interpretação explícita do ser deste ente dotado de extensão (HEIDEGGER, 2005, p. 148).

Na desconstrução dos valores e pressupostos cartesianos operada por Heidegger, tornam-se claros os fundamentos ontológicos da determinação do mundo como res extensa. O esforço revela que, no caminho de Descartes, a ideia de substancialidade não é esclarecida no sentido de seu ser, ou seja, não se pergunta pela fundamentação da orientação que entende que ser é tudo aquilo que permanece o mesmo, que sulbjaz préexiste e subsiste à experiência. Além disso, seguindo o desvio pela propriedade principal da substância, a ideia própria de substância é tomada e apresentada como uma espécie de limite para a investigação filosófica, como algo que fosse, por si só, impossível de esclarecimento e que devesse ser admitido por todos como pressuposto.

A maior consequência dessa perspectiva é a constituição de um homem com uma essência, entendida como substância, que é separada daquilo que são as coisas, ou seja, daquilo que é o mundo. Desse modo, a natureza só existe como uma extensão daquilo que é homem, encontra-se em verdadeira oposição ao espírito e tem como única vocação ser dominada. Com efeito, os subsídios e as bases para que se cumpra a tarefa de controlar e se assenhorar da realidade, encontram-se no único lugar seguro disponível: a consciência.

\begin{abstract}
A segurança da modernidade europeia é a certeza com a qual ou na qual o eusujeito substância se representa a si próprio - auto-asseguramento. Como algo seguro em relação a si próprio e na clareza e distinção de sua auto-representação é esta auto-certeza elevada a critério de verdade - "cogito ergo sum". Critério de verdade significica: a determinação fundamental a partiir da qual é decidido sobre a realidade do real, sobre a consistência ontológica da objetividade do objeto, pois como objetividade do objeto o sujeito-substância já decidiu ser a realidade do real (FOGEI, 1998a, p. 111).
\end{abstract}

Na tentativa de se estabelecer a ordem, de se evitar o erro e o caos de um mundo "mundano" e simplesmente aparente, esse horizonte estruturou um outro mundo, na razão. Esse outro mundo - um mundo primeiro - nos seria acessível somente pelo pensamento e seria o fundamento do mundo aparente. É preciso sempre desconfiar das aparências, pois os sentidos podem nos enganar. Como causa essencializada, essa espécie de arquivo com todas as substâncias, seria perfeito, e, portanto, não contaria com a presença do erro ou do engano promovidos pelos sentidos. Por isso, o mundo de essência é mais confortável: nele não há a "sujeira" da dimensão sensível da existência para nos ludibriar. Sendo assim, somente os conceitos moldados pela razão, as ideias presentes na consciência, é que são as fontes confiáveis de acesso à realidade. Uma estrutura e tanto para calcar o lugar que a ciência do cálculo e a tecnologia ocupam hoje entre os diversos modos de apropriação do real.

Expostos a origem (gênese) e o encaminhamento (destino) da compreensão moderna de espaço como extensão, resta-nos, agora, nos aproximarmos ainda mais de um outro modo de entendimento do que vem a ser mundo, homem e a sua relação com o espaço: a compreensão heideggeriana.

\title{
3. A compreensão heideggeriana de espaço
}

É em busca da mundanidade do mundo que a investigação heideggeriana, da analítica existencial, se movimenta no terceiro capítulo de Ser e Tempo, parte I. Na tentativa de dar conta do espaço, enquanto fenômeno originário da pre-sença, o autor define que é preciso percorrer três etapas: 1) compreender a espacialidade do manual intramundano, ou seja, entender como e em que medida nossa relação com os entes é sempre espacial (§22); 2) investigar a espacialidade do ser-no-mundo, isto é, explicitar a propriedade espacial dessa dimensão estrutural da pre-sença $(\$ 23)$; e 3) compreender ontologicamente a espacialidade da pre-sença e o espaço; dito em outras palavras: 
esclarecer como se insere a espacialidade no processo de constituição ontológica do que é homem e mundo e o que é o próprio do espaço (\$24). A divisão cumpre apenas função didática, já que pretende apenas evidenciar desdobramentos de um único e mesmo fenômeno, e não afirmar a anterioridade de algum desses horizontes da existência.

Nessa tarefa, o objetivo é esclarecer que, na nossa relação com quaisquer que sejam os "objetos", há sempre uma dimensão espacial na qual "as coisas" se constituem, isto é, em que o "mundo" se mostra para nós" uma espacialidade na qual os entes se realizam. A própria estrutura ser-no-mundo, como momento constitutivo do Dasein, já aponta para a espacialidade que integra essa unidade fundamental de existência. Ser-nomundo é um modo de ser que aponta necessariamente para uma certa localização/espacialização; é ser sempre inserido em um mundo, de modo fundamental, e numa certa ocupação ${ }^{3}$, não havendo antes, ou fora dessa experiência de inserção. Isso quer dizer que homem e mundo, o que inclui o conjunto dos entes intramundanos, já que não são algo cuja essência antecede a existência, são sempre originariamente espaciais, visto que a pre-sença é espacial por natureza.

No primeiro passo descrito por Heidegger, entender a espacialidade do manual intramundano significa compreender que, em vez de conjunto de substâncias inseridas no espaço, os entes sempre se manifestam para nós no que o autor chama de circunvisão ${ }^{4}$, que aponta para a dimensão espacial do próprio modo de realização de realidade. Na experiência, isto é, de maneira não-tematizada, nossa relação com os entes é sempre desde uma certa ocupação que revela, na circunvisão, a manualidade do ente intramundano. Isso quer dizer que, cotidianamente, os entes com os quais nos relacionamos numa lida, numa tarefa, se realizam sempre na forma de um instrumento, ou seja, desde um "para que", na medida em que servem ou não servem para cumprir com uma determinada tarefa. A mesa, a cadeira, o lápis, o livro, o caderno, o aparelho de ar condicionado, e até mesmo a própria sala de estudos, por exemplo, não se revelam objetivamente como sendo entes independentes e descontextualizados, muito menos podem ser determinados ontologicamente estabelecendo-se o conjunto de intervalos objetivos existentes entre eles, mas o são na medida em que servem para estudar. São seres constituídos de manualidade na proporção em que estão sempre à mão para o cumprimento de uma determinada tarefa.

Nessa interpretação, nossa relação com os "objetos" é sempre, e a cada vez, desde uma ocupação, isto é, se realiza a partir de um certo fazer, de uma atividade, num exercício que guia e produz uma vasta rede de remissões de sentidos, no qual a pre-sença é o centro irradiador dessas relações. Esta teia de significados inclui a sua manualidade, mas também a dimensão espacial dos "objetos": seu "para que", assim como seu "onde", sua localização.

Nunca nos é dado, de início, uma multiplicidade tridimensional de possíveis posiçōes preenchidas por coisas simplesmente dadas. Essa dimensionalidade do espaço ainda se acha encoberta na espacialidade do que está à mão. 0 local "em cima" é o local "no teto", o "embaixo" é o no chão, o "atiás" é o junto à porta; todos os onde são descobertos e interpretados na circunvisão, através das passagens e caminhos do modo de lidar cotidiano, e não constatados e enumerados numa leitura de medições do espaço (HETDEGGER, 2005, p. 151).

\footnotetext{
${ }^{3}$ Na nota (N11), Márcia Schuback indica que: "Não sendo uma substância, a pre-sença sempre se dá num exercício. Exercício indica e cumpre um centro irradiador de relações. Os dois planos em que, predominantemente, se desenvolve o exercício da pre-sença promovem relações com dois modos de ser da existência: relaçóes com o modo de ser dos entes simplesmente dados e relaçốes com entes dotados do modo de ser da pre-sença. Da perspectiva de seu centro irradiador, ambos os planos se caracterizam pela dinâmica própria de pre-sença" (HEIDEGGER, 2005, p. 312)。

${ }^{4}$ Sobre a circunvisão, (N18), Schuback aponta que "A construção do mundo cotidiano das ocupações não é cega, mas guiada por uma visão de conjunto, a circunvisão, que abarca o material, o usuário, o uso, a obra, em todas as suas ordens" (HEIDEGGER, 2005, p. 314).
} 
Sendo assim, em vez de condição de possibilidade, espécie de substância a priori de tudo o que existe, o espaço, nessa perspectiva, ganha uma outra natureza, já que é parte constituinte e inseparável da dinâmica que realiza homem e mundo e não algo anterior a ela. É numa certa ocupação, que determina um modo de manifestação do que é o mundo com o qual nos relacionamos, e também define aquilo que é o homem, que se realiza o fundamento ontológico da existência, e isso, é claro, como solo essencial, determina também, ao mesmo tempo, o modo de realização de espaço.

Dessa maneira, o onde, ou seja, o lugar no espaço, de cada ente com o qual lidamos cotidianamente, sempre nos diz respeito, é, em toda e a cada vez, "para nós"; o onde é descoberto, isto é, se realiza, desde a circunvisão, a partir de uma determinadla visão de conjunto. Isso quer dizer que, ontologicamente, nenhuma medição em metros, centímetros e milímetros, por mais precisa que seja, pode revelar o fenômeno da nossa relação com os entes, na sua dimensão espacial, muito menos serve para esclarecer o espaço nele mesmo. Sendo assim, o que é primeiro, ou seja, o que é gênese de todo real, em sua dimensão espacial, é um determinado modo como os entes são desvelados na circunvisão. É em ưma certa ocupação, em uma reunião que responde por certas necessidades, e que tem o modo de ser da pre-sença, que a dimensão espacial de todos os entes se desencobre para nós.

O que se está querendo apontar é que os entes mais próximos, os "objetos" com os quais lidamos cotidianamente, têm a propriedade de se mostrarem desde um "para que", daí a natureza instrumental dos entes à mão (manual). Desse modo, até mesmo a distância e a proximidade correspondem não à uma medição objetiva dos intervalos existentes entre os entes intramundanos e nós, para quem os entes se manifestam, mas estão relacionados com a ocupação, ou seja, são o resultado de um determinado exercício, que determina não somente sua inclusão como instrumento, como também define sua proximidade.

O ente "à mão" sempre possui uma proximidade diferente que não se estipula medindo distâncias. Essa proximidade regula-se a partir do uso e manipuilação "a se levar em conta" na circunvisão. A circunvisão da ocupação fixa o que, desse modo, está próximo também no tocante à direção em que o instrumento é, cada vez, acessível. A proximidade direcionada do instrumento significa que ele não ocupa uma posição no espaço, meramente localizada em algum lugar, mas que, como instrumento, ele se acha, essencialmente, instalado, disposto, instituído e alojado (HEIDEGGER, 2005, p. 150).

É claro que tardiamente, pode-se tematizar nossa relação com os entes, em sua propriedade espacial, desde um encaminhamento objetivante da realidade. $\mathbb{E}$ verdade que também é possível medir a realidade, com a ajuda dos mais avançados aparelhos tecnológicos, com muita precisão, na tentativa de descrever, pormenorizadamente, a "localização" de cadla um dos entes com os quais entramos em relação, em cada experiência. Mais esse esforço responde a um encaminhamento no qual de um lado haveria os "objetos" e do outro os "sujeitos", para os quais os objetos se manifestam autonomamente. Sendo assim, a natureza da dimensão espacial da existência seria independente de um "para quem" e, desse modo, não somente poderia, como também deveria ser medida e determinada em metros. Só que o que se quer apontar aqui é que qualquer precisa medição não é capaz de desencobrir o fenômeno da espacialidade, já que sempre chega depois, realiza uma interpretação ôntica, isto é, revela o resultado e não consegue desencobrir a dinâmica desde a qual o espaço se espacializa.

Só que essa interpretação desobjetivante do espaço nada tem a ver com subjetivismo. Não é porque os entes se manifestam espacialmente sempre para nós que essa dimensão da existência passa a ser o resultado da vontade ou do arbítrio do homem. Dizer que o espaço não é originariamente objetivo não significa que essa dimensão constitutiva e inseparável de existência seja determinada pelo "para quem" o espaço se espacializa. O homem é lugar de realização de realidade sem que com isso se 
torne o senhor desse processo. O que se quer indicar é que, em uma determinada circunvisão, o que está objetivamente mais próximo pode ser o mais distante e o que possui maior intervalo espacial, por outro lado, também pode se revelar como sendo, na verdade, o mais próximo. A visão de conjunto é que determina, em úlitima innstância, distanciamento e proximidade.

Seguindo a orientação prévia pela "natureza" e pelos intervalos entre as coisas, medidos "objetivamente", tem-se a tendência de considerar tais avaliações e interpretações do distanciamento como "sulbjetivas". Trata-se, porém, de uma "subjetividade" que talvez descubra o mais real da "realidade" do mundo, a qual nada tem a ver com uma arbitrariedade "subjetiva" nem com apreensões subjetivistas de um ente "em si" diverso. O dis-tanciamento guiado por uma circunvisão na cotidianeidade da pre-sença descobre o ser-em-si do "mundo verdadeiro", isto é, de um ente junto ao qual a pre-sença, existindo, já sempre está (HEIDEGGER, 2005, p. 155)。

Em vez de produto, de resultado da medição em metros; no lugar de espaço como substância, é atrás da força de realização, isto é, do vigor que realiza o espaço, que Heidegger concentra os esforços e procura descrever fenomenologicamente a natureza das "coisas". Nesse sentido, até mesmo o espaço entendido como distância objetiva, isto é, o que distraidamente compreendermos como intervalos mensuráveis entre os entes, também se realiza desde a estrutura ser-no-mundo. Desde uma tarefa, na lida cotidiana, os objetos podem estar mais próximos ou mais distantes, a depender da ocupação. Nem sempre o que se pretende mais "próximo" objetivamente, isto é, encontra-se a menos centímetros de "distância", revela-se como o mais próximo no mundo circundante.

É a ocupação guiada pela circunvisão que decide sobre a proximidade e distância do que está imediatamente à mão no mundo circundante. As ocupações se atêm previamente ao que está mais próximo e regula os dis-tanciamentos (HEIDEGGER, 2005, p. 156).

Reforçamos que não é porque não objetiva o espaço, ou seja, não é porque não compreende o fenômeno do espaço como tendo uma existência autônoma dos "sujeitos" que essa compreensão funda o princípio de realização do espaço na determinação subjetiva. Apesar de termos afirmado anteriormente, que a espacialidade, enquanto modo de realização de espaço, depende da circunvisão, ou seja, de uma visão de conjunto que leva em consideração o material, o usuário, o uso, a obra, em todas as suas ordens, o "sujeito para quem as coisas são", não determina a natureza do espaço, ou do que quer que seja, arbitrariamente. $\mathrm{O}$ homem é o lugar de manifestação de toda a realidade, mas não é o responsável por ela, não é seu princípio de realização. Só se compreende a negação da objetividade como sendo, automaticamente, a afirmação da subjetividade, se não se conseguir superar a cisão metafísica de homem e mundo, ou seja, se não se questionar a separação sujeito-objeto como fundamento de todo o real, o que inclui, naturalmente, a compreensão de espaço, como "objeto".

O que a citação acima quer apontar é que, na experiência, até mesmo os intervalos entre os objetos, passam, por princípio, pela totalidade do fenômeno de unidade já indicado anteriormente: a estrutura ser-no-mundo. E o que essa estrutura quer descrever, mais uma vez, nada tem a ver com subjetivismo. Não há primeiro homem e depois mundo, como se a natureza de cada um desses componentes já chegasse pronta e resolvida, ou como se o sujeito pudesse projetar um mundo, incluindo a dimensão espacial, do modo que melhor lhe convier. O homem é o "para quem" o espaço se manifesta, sem que com isso ele se torne a causa dessa manifestação. A rigor, é a circunvisão que "tem" o homem, que o afeta e constitui um momento de sua realização e não o contrário.

Se quer indicar que, fenomenologicamente, até mesmo a distância responde a mesma dinâmica na qual, é desde uma visão de conjunto, que se guia e se governa a experiência. Sendo assim, os óculos, por exemplo, são um instrumento com o qual nos relacionamos na tarefa de apreciar uma obra de arte, constituindo-se até mesmo como condição de possibilidade dessa ocupação, a depender do grau de deficiência visual. Só que o que se pretende como sendo o mais próximo, já que objetivamente os óculos ficam 
apoiados no nariz, bem em frente aos olhos, pode se manifestar como sendo mais distante do que o próprio quadro na parede que é apreciado. Tão próximo objetivamente e tão distante quando se pensa a experiência. O anteparo de vidro, a luminária que ilumina o quadro, muitas vezes podem ser considerados instrumentos mais próximos no exercício de ver uma obra de arte do que os óculos na ponta do nariz.

Heidegger afirma que o segundo passo da tarefa de repensar o sentido do espaço, enquanto fenômeno originário da pre-sença, é investigar a espacialidade do serno-mundo. Já indicamos que é por realizar-se como ser-no mundo, que a pre-sença sempre cumpre um espaço, ou seja, se efetua numa dimensão espacial que lhe é própria.

De acordo com o seu ser-no-mundo, a pre-sença já sempre dispõe previamente, embora de forma implícita, de um espaço já descoberto. Em contrapartida, o espaço em si mesmo fica, de início, encoberto no tocante às possibilidades puras de simples espacialidades de alguma coisa. O fato de o espaço se mostrar essencialmente num mundo, năo decide sobre a modalidade de seu ser (HEIDEGGER, 2005, p. 162)。

o que a citação quer apontar é que a dimensão espacial da constituição ontológica de homem e mundo pode se "esconder", num primeiro momento, na forma de espacializações dos entes com os quais nos relacionamos. Entretanto, apesar de se deixar ver, isto é, mesmo que o espaço cotidianamente se revele sempre em modos espaciais de "objetos" com os quais lidamos em uma certa atividade, em um determinado contexto, o espaço, nele mesmo, não é nada de separado daquilo que é mundo muito menos é a sua condição de possibilidade. Reforçamos a ideia de que não existe primeiro o espaço, depois o mundo; não é porque se revela sempre num mundo possível, ou seja, porque sempre apreendemos o espaço em um determinado contexto, que o modo de ser do espaço seja "algo" da ordem do que é passível de objetivação.

\section{Conclusão}

Para superar a compreensão de espaço como extensão, cunhadla na modernidade, é preciso investigar a dimensão ontológica do espaço, o que significa entender que sua dinâmica de realização responde ao mesmo fundamento ontológico que realiza homem e mundo. O ser do espaço nada tem a ver com uma desmundanização dos entes com os quais lidamos, para se encontrar nos intervalos dos entes intramundanos uma essência substancial, mas é o espaço que está no mundo na medida em que ele é, justamente, uma dimensão constitutiva da pre-sença. O ser-no-mundo como estrutura desde a qual o Dasein vigora, já sempre descobriu um espaço não havendo nada fora ou além disso como determinação da espacialidade do mundo.

No fenômeno do espaço, não se pode encontrar nem a única nem a determinação ontológica primordial do ser dos entes intramundanos. Tampouco ele constitui o fenômeno do mundo. O espaço só pode ser concebido recorrendo-se ao mundo. Não se tem acesso ao espaço, de modo exclusivo ou primordial, através da desmundanização do mundo circundante. A espacialidade só pode ser descoberta a partir do mundo e isso de tal maneira que o próprio espaço se mostra também um constitutivo do mundo, de acordo com a espacialidade essencial da pre-sença, no que respeita à sua constituição fundamental de ser-no-mundo (HEIDEGGER, 2005, p. 163).

Com isso se quer afirmar que o espaço é uma dimensão da existência, e, por isso, não deveria ser compreendido como sendo o fundamento ontológico dos entes com os quais lidamos, muito menos como equivalente a uma espécie de "essência primeira" do mundo. A essa altura da exposição já temos as bases para reafirmar o que expusemos no início deste artigo: o espaço não está no sujeito, sendo determinado por ele, nem o mundo está no espaço, como se houvesse primeiro o espaço, como condição de possibilidade e depois o mundo. É o espaço que está no mundo, já que o ser-no-mundo constitutivo da pre-sença já descobriu sempre um espaço. É no fenômeno de unidade da 
estrutura ser-no-mundo, que Heidegger localiza o princípio, o fundamento ontológico de existência. Logo, é somente desde essa estrutura fundamental que se pode compreender não-metafisicamente o modo de ser, a natureza do espaço.

Com essa nova perspectiva, que insere o espaço na própria dinâmica que realiza homem e mundo, procura-se explicitar o modo de ser fundamental da experiência restituindo, a esse movimento realizador de realidade, a sula dimensão espacial. O espaço passa, então, a ser entendido como parte constitutiva, não somente do que chamamos de "mundo em que vivemos", como também daquilo que são os entes com os quais nos relacionamos, e daquilo que nós mesmos somos.

\section{Referências}

FOGEL, Gilvan. "Do 'coração-máquina' - Ensaio de aproximação à questão da tecnologia". In: Da Solidão Perfeita: escritos de filosofia. Petrópolis, RJ: Vozes, 1998a. pp. 91-130.

"Martin Heidegger, et coetera e a questão da técnica". In: Da Solidão Perfeita: escritos de filosofia. Petrópolis, RJ: Vozes, 1998b. pp. 131-170.

HEIDEGGER, Martin. Qu'est-ce qu'une chose? Tradução: Jean Reboul. Paris: Gallimard, 2011.

Ser e Tempo. Parte I. 14a ed. Tradução: Márcia Sá Cavalcante Schuback. Petrópolis, RJ: Vozes, 2005.

NUNES, Benedito. Heidegger e Ser e Tempo. 2a. ed. Rio de Janeiro: Jorge Zahar, 2004.

Doutor em Filosofila (UF'RJ, 2012)

Professor do Departamento de Comunicação e do PPG de Filosofia (UFES)

E-mail: rafaelpaesh@gmail.com 